Mitral valve: treatment

Extended Abstract

\title{
Predictors and timing of permanent electrostimulators implantation after heart valve surgery
}

\section{(1) Petar Pekić*}

University Hospital "Sveti Duh", Zagreb, Croatia
KEYWORDS: atrioventricular block, electrostimulator, valve replacement. CITATION: Cardiol Croat. 2018;13(5-6):192. | https://doi.org/10.15836/ccar2018.192

*ADDRESS FOR CORRESPONDENCE: Petar Pekić, Klinička bolnica „Sveti Duh“, Sv. Duh 64, HR-10000 Zagreb, Croatia. E-mail: ppekic@gmail.com

ORCID: Petar Pekić, https://orcid.org/0000-0003-0084-3465

Background: The incidence of bradyarrhytmias after cardiac surgery is approximately $15 \%$. Approximately, $3-5 \%$ of patients undergoing a valvular surgical procedure require the installation of a permanent electrostimulator prior to hospital discharge ${ }^{1}$

Discussion: Calcificating aortic valve disease is recognized as the cause of an atrioventricular (AV) block. Valvular interventions related to the repair of the perimembraneous septum represent the risk of AV block formation, which is therefore the most common bradyarrhythmia that can be associated to the surgical procedure. The block at or below the bundle of Hiss results in more permanent forms of the AV block which often implies the insertion of an electrostimulator. Surgical aspects that carry the risk of a persistent postoperative AV block are related to multiple valve operation at one and the same time, "re-do" operations and prolonged time to the cardiopulmonary bypass ${ }^{2}$. Of all valves, the replacement of the tricuspid valve alone or in combination with the intervention on the second valve carries the highest risk of the AV block. In one study, the pre-existing right branch block was a better predictor of the postoperative AV block than the left branch block. Preoperative PQ prolongation and age over 70 were additional predictive factors. A smaller percentage (about 10\%) of bradyarrhytmias after valvular surgery is due to dysfunction of the sinus node and the "tachy-brady" syndrome with atrial fibrillation episodes. Sinus node dysfunction has a better prognosis compared to the AV block. The fact that the conduction system in some cases still recovers has led to today's practice of imaging an electrostimulator, which is delayed up to 10 days after the valve operation. Non-surgical, percutaneous valvular interventions do not benefit in the prevention of post-operative bradyarrhytmias. On the contrary, the transcutaneous aortic valve replacement (TAVR) has a higher incidence of AV block compared with the open-heart surgery. Approximately, 15-20\% patients require implantation of the electrostimulator in the early postoperative period ${ }^{3-5}$.

Conclusion: Technological improvements in the artificial valves design and setting technique in relation to the root of the aorta could lead to a reduction in incidence of damage to the conduction system immediately after the operation. Regardless, the progressive nature of the congenital system disease associated with chronic valvular disease is unlikely to be slowed down by surgical relief of valve disease due to its multifactorial pathophysiology and progressive fibrosis.

\section{RECEIVED:}

May 3, 2018

ACCEPTED:

May 10, 2018

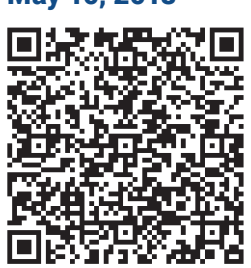

LITERATURE IIIIIIIIIIIIIIIIIIIIIIIIIIIIIIIIIIIIIIIIIIIIIIIIIIIIIIIIIIIIIIIIIIIIIIIIIIIIIIIIIIIIIIIIIIIIIIIIIIIIIII

1. Gordon RS, Ivanov J, Cohen G, Ralph-Edwards AL. Permanent cardiac pacing after a cardiac operation: predicting the use of permanent pacemakers. Ann Thorac Surg. 1998 Nov; 66(5):1698-704. https://doi.org/10.1016/S0003-4975(98)00889-3

2. Koplan BA, Stevenson WG, Epstein LM, Aranki SF, Maisel WH. Development and validation of a simple risk score to predict the need for permanent pacing after cardiac valve surgery. J Am Coll Cardiol. 2003 Mar 5;41(5):795-801. https://doi.org/10.1016/S0735-1097(02)02926-1

3. Van Mieghem NM, Head SJ, de Jong W, van Domburg RT, Serruys PW, de Jaegere PP, et al. Persistent annual permanent pacemaker implantation rate after surgical aortic valve replacement in patients with severe aortic stenosis. Ann Thorac Surg. 2012 0ct;94(4):1143-9. https://doi.org/10.1016/j.athoracsur.2012.04.038

4. Habicht JM, Scherr P, Zerkowski HR, Hoffmann A. Late conduction defects following aortic valve replacement. J Heart Valve Dis. 2000 Sep;9(5):629-32. PubMed: https://www.ncbi.nlm.nih.gov/pubmed/11041175

5. Zakhia Doueihi R, Leloux MF, De Roy L, Kremer R. Permanent cardiac pacing for prolonged second and third degree atrioventricular block complicating cardiac valve replacement. Acta Cardiol. 1992;47(2):157-66. PubMed: https://www.ncbi.nlm.nih.gov/pubmed/1615742 $\square$ Cardiologia Croatica 2018;13(5-6):192. 